\title{
The System Design and Realization on Inclusive Finance Economic Influence based on the Feature Extraction and Data Fusion
}

\author{
Chao Zhou* \\ Department of Economics and Management, China University of Labor Relations, Beijing, 100048, China \\ 18618159649@126.com \\ Received: 1 December 2021; Rvised: 2 January 2022; Accepted: 2 February 2022
}

\begin{abstract}
Inclusive finance is a financial system that can effectively and comprehensively provide services to all social classes and groups. Design an inclusive financial economic impact system based on feature extraction and data fusion. Based on the perspective of factor market, product market and financial market, the system structure is designed based on the level of information fusion, and the system is divided into data layer, feature layer and decision layer. Collect different information from the sample data of 31 provinces across the country and perform information fusion to establish a regression model to maximize the information retention rate. Explore the influence of the three market development degrees and the development level of inclusive finance on the high-quality development of the regional economy, and improve the robustness of information feature fusion. The results show that the development level of inclusive finance and the development degree of the three markets have a significant role in promoting the high-quality development of the regional economy. Inclusive finance can promote the high-quality development of the regional economy by optimizing the development of the "three markets".
\end{abstract}

Keywords: information fusion, system design inclusive finance, feature extraction, moderating role

\section{Introduction}

\subsection{Research Background}

As the largest developing country in the world, financial exclusion is widespread in China, which restricts economic and industrial development to a certain extent. As an important measure of China's economic policy reform, inclusive finance aims to establish an effective, comprehensive and convenient financial system that provides services to all strata and groups of society, so as to promote regional economic development, eliminate unbalanced financial development, and achieve the goal of social equality. At the same time, "factor market, product market, and financial market" are the three major markets for economic operation [1]. The three markets in the region are interconnected and circulated, which also plays a key role in promoting the highquality development of the regional economy. Therefore, under the background of the current deep reform of my country's market economic system, combined with the development of inclusive finance and the status quo of the three major markets, the discussion on the promotion of high-quality development of regional economy by inclusive finance is a new research perspective and has important practical significance [2].

Since the introduction of financial inclusion, scholars at home and abroad have achieved rich research results [3]. The development model of inclusive finance can be classified into two ways: government-led and marketled. Zhao \& Chen believe that the development of financial inclusion requires strong government intervention to promote benign feedback between financial inclusion and the market, and correct market failures [4]. Tian Jianying, Huang Chunxu [5], Wang Xiaowen et al. [6] believe that the government should try to avoid excessive intervention and let the market play a decisive role in resource allocation, so as to avoid market distortion and reduce the service efficiency of inclusive finance. "Factor market, product market, and financial market" are the three major markets for economic operation, and the relationship between the development level of the three major markets and the high-quality development of the regional economy has also been a hot topic of discussion among scholars in recent years. In general, the academic community generally believes that the level of factor market allocation has an important impact on economic development.

At present, the Web has developed into a distributed information space with hundreds of millions of pages, and the amount of financial information on the network is also very complex [7]. How to quickly and effectively discover valuable knowledge and information from the information space has become a hot issue in the field of information technology [8]. The object of feature extraction is web text, which is one of the most critical links in 
web page classification. It has the functions of reducing the dimension of vector space, simplifying calculation, preventing overfitting, and removing noise. The quality of feature extraction directly affects the accuracy of classification.

At present, the commonly used feature extraction algorithms are: text frequency (DF), word frequency (IVF), information gain (IG), mutual information (MI), expected cross entropy, text evidence weight, odds ratio, etc [9]. All of them are based on the assumption of feature independence, and through the constructor, each feature in the feature set is independently evaluated, and each feature is scored, and feature items are selected according to the size of the score [10]. These algorithms are widely used in Web text mining, but they also have shortcomings and deficiencies.

In the past, the extraction system based on variational modal decomposition and independent component analysis was mainly used in the extraction of information features [11]. However, when the above systems obtained operation information, the data source was relatively single, and the incomplete operation information led to certain limitations in the accuracy of feature extraction [12]. In response to this problem, it is particularly necessary to design an inclusive financial economic impact system based on feature extraction and data fusion, and to obtain high-precision data.

\section{Related Work and Theories}

\subsection{Overview of Financial Inclusion}

Inclusive finance refers to providing appropriate and effective financial services at an affordable cost to all social strata and groups in need of financial services based on the requirements of equal opportunities and the principles of business sustainability, and improving the availability of financial services by lowering the threshold. It is of great significance for expanding consumption, stimulating investment, and improving the balance of regional economic development [13].

The integration of financial inclusion and the development of the three markets will generate new impetus for regional economic growth. The promotion of inclusive finance is helpful in improving the level of urbanization and infrastructure construction. At the same time, in order to promote orderly competition and cooperation in the product market, we should not only focus on the independent development of some regions, but also need to cooperate with surrounding regions to form a good competitive relationship. The main service target of inclusive finance is the "tail" group, so it can promote the development of regions with relatively weak product market competitiveness, and play a supporting role in the cooperation and interaction between regional product markets [14]. At the same time, problems caused by economic development and differences in regional income levels have gradually emerged. Therefore, it is very important to promote the marketization process and the financial opening process in different regions and stages according to the economic development status and regional income level differences. The depth of the financial market serving the real economy will help improve the efficiency of the financial market in promoting high-quality development of the regional economy. Therefore, inclusive finance can promote the high-quality development of the regional economy by optimizing the development of the "three markets".

\subsection{Text Feature Extraction Methods}

BNS is a new feature extraction algorithm suitable for text classification operations. It uses probability and statistical methods to measure and compare the significance of items with respect to the category distribution. The formula is:

$$
\begin{aligned}
& \mathrm{BNS}(\mathrm{t})=\mathrm{F}^{-1}(\mathrm{tpr})-\mathrm{F}^{-1}(\mathrm{fpr}) \\
& \mathrm{tpr}=\mathrm{tg} /(\mathrm{tp}+\mathrm{fn}) \\
& \mathrm{fpr}=\mathrm{fp} /(\mathrm{fp}+\mathrm{ta})
\end{aligned}
$$

The BNS algorithm uses a random normal distribution curve to model the features in each text, and uses the limit area of the endpoints under the normal curve as a measure of the degree of correlation between the feature entry and the class. The greater the degree of correlation between the feature entry and the class, the distance between the endpoints of the positive class and the endpoints of the negative class is farther, and the BNS value is a measure of the difference between the two endpoints. Experiments on English samples show that the BNS 
method can solve the problem of data set skew very well.

Zhu Xiangyu et al. used dual evaluation functions to extract text features. Chen Tao et al. used IIG and LSI to extract and recluster text combined features. The research shows that this idea can effectively reduce the feature dimension, but it cannot solve the problem of data set skew., and which combination method is adopted to achieve the optimal solution while ensuring the advantages of the combination algorithm is the key and difficult point.

\subsection{Introduction to Data Fusion}

Data fusion is a multi-level, multi-faceted process of detecting, combining, correlating, estimating, and combining multi-source data to achieve scarce state and identity estimates, as well as complete and timely situational assessments and Threat estimation. According to the difference of the data to be fused, it can be divided into two categories: data-level fusion and decision-level fusion. The neuron data fusion system is shown in the Fig. 1.

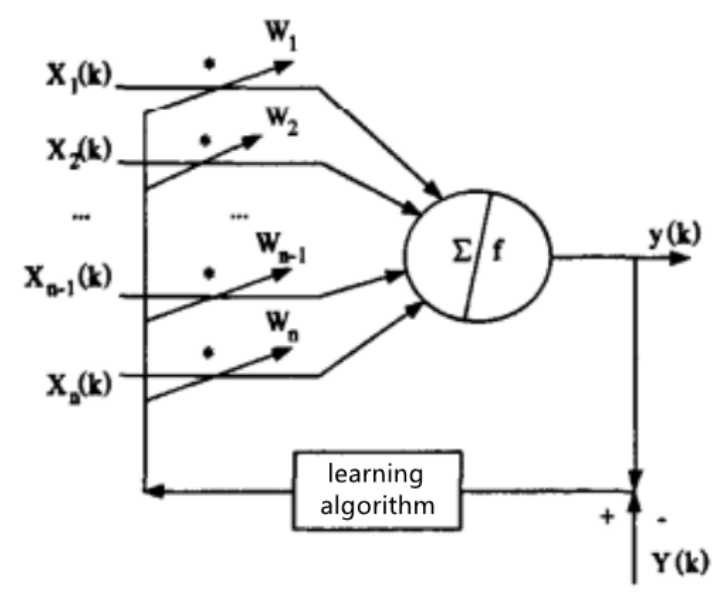

Fig. 1. Neuron data fusion system

Commonly used data fusion methods include: weighted average method, Bayesian estimation, multi-Bayesian estimation, Kalman filter, statistical decision theory, fuzzy reasoning, neural network and rough set methods. For these methods, many scholars have done a lot of research. But these methods mainly fuse data at the decisionmaking level, and less at the data level. Data fusion includes homologous data fusion and multi-source data fusion. Compared with homologous data fusion, multi-source data fusion methods are more widely used.

Using high-dimensional feature vectors for classification requires a lot of computational workload, and highlevel samples need to be processed for dimensionality reduction. Commonly used dimensionality reduction methods can be divided into linear and nonlinear dimensionality reduction, mainly including principal component analysis (PCA), multidimensional scaling analysis (MDS), and algorithms based on manifold learning proposed in recent years, such as Isomap, local linear embedding (LLE), Laplace eigenmap (LE), etc.

\section{Research Design}

\subsection{System Structure Design}

In the process of obtaining information characteristics of the financial inclusion economic impact system, the results obtained are different, so the integration of these different results is very important. Select 31 provinces in the country from 2011 to 2018 as samples, grasp the relationship between the five development concepts and economic growth, select relevant indicators to measure the five dimensions of innovation, coordination, green, openness and sharing, and use the entropy weight method to construct provincial Regional economic high-quality development evaluation indicators. The selection of relevant indicators is shown in Table 1. 
Table 1. Economic high-quality evaluation index system

\begin{tabular}{|c|c|c|c|}
\hline target layer & $\begin{array}{l}\text { Criterion } \\
\text { layer }\end{array}$ & Indicator layer & unit \\
\hline \multirow{18}{*}{$\begin{array}{l}\text { high-quality } \\
\text { development }\end{array}$} & \multirow{3}{*}{ innovation } & R\&D input intensity & $\%$ \\
\hline & & Technical market turnover & billion \\
\hline & & The number of invention patents owned by 10,000 people & / \\
\hline & \multirow{4}{*}{$\begin{array}{l}\text { Coordina- } \\
\text { tion }\end{array}$} & urban-rural income ratio & $\%$ \\
\hline & & urban-rural consumption ratio & $\%$ \\
\hline & & The proportion of secondary industry & $\%$ \\
\hline & & The proportion of the tertiary industry & $\%$ \\
\hline & \multirow{6}{*}{ green } & Forest cover rate & $\%$ \\
\hline & & Green coverage in built-up areas & $\%$ \\
\hline & & Harmless treatment rate of domestic waste & $\%$ \\
\hline & & $\begin{array}{l}\text { Proportion of Environmental Protection Expenditure to Fiscal } \\
\text { Expenditure }\end{array}$ & $\%$ \\
\hline & & Number of days with air quality at or better than Grade 2 & / \\
\hline & & Number of foreign-invested enterprises & 1 \\
\hline & \multirow{5}{*}{ shared } & Number of beds in medical and health institutions & 1 \\
\hline & & Per capita public library holdings & 1 \\
\hline & & Public transport vehicles per 10,000 people & 1 \\
\hline & & Number of urban workers participating in endowment insurance & $\begin{array}{l}10,000 \\
\text { people }\end{array}$ \\
\hline & & $\begin{array}{l}\text { The number of people insured by the basic medical insurance for } \\
\text { urban workers }\end{array}$ & people \\
\hline
\end{tabular}

Digital Inclusive Finance Index (Inclusive): The digital financial inclusion index calculated by the Digital Finance Research Center of Peking University is selected to measure the development level of provincial inclusive finance.

Market development level (Factor, Product, Finance): Select the subdivision indicators of the marketization index of China's provinces compiled by Fan Gang et al., that is, the product market development score, the factor market development score and the financial market development score to measure the provincial market development level.

In addition to the development level of digital financial inclusion and the development levels of the three markets, this paper also adds the following control variables to reduce the deviation of the estimated results caused by the omission of variables:

Trade openness (Open): In the era of free trade, the level of foreign trade has an important impact on economic growth. This paper selects the proportion of total provincial import and export trade in GDP to measure the level of local trade openness; Fiscal: Fiscal, as an important means for local governments to ensure economic growth and maintain economic stability, plays an important role in regional economic development. Role. This paper selects the proportion of provincial fiscal expenditure to GDP to measure the level of government fiscal expenditure; Urbanization level (Urban): In recent years, the development concept and performance concept of each local government's "heavy urbanization process" make the level of urbanization affect the regional economy. The effect of growth is increasingly not negligible. This paper selects the proportion of urban population in the province to measure the level of urbanization. The structure of the information feature extraction system is designed based on the level of information fusion, as shown in Fig. 2. 


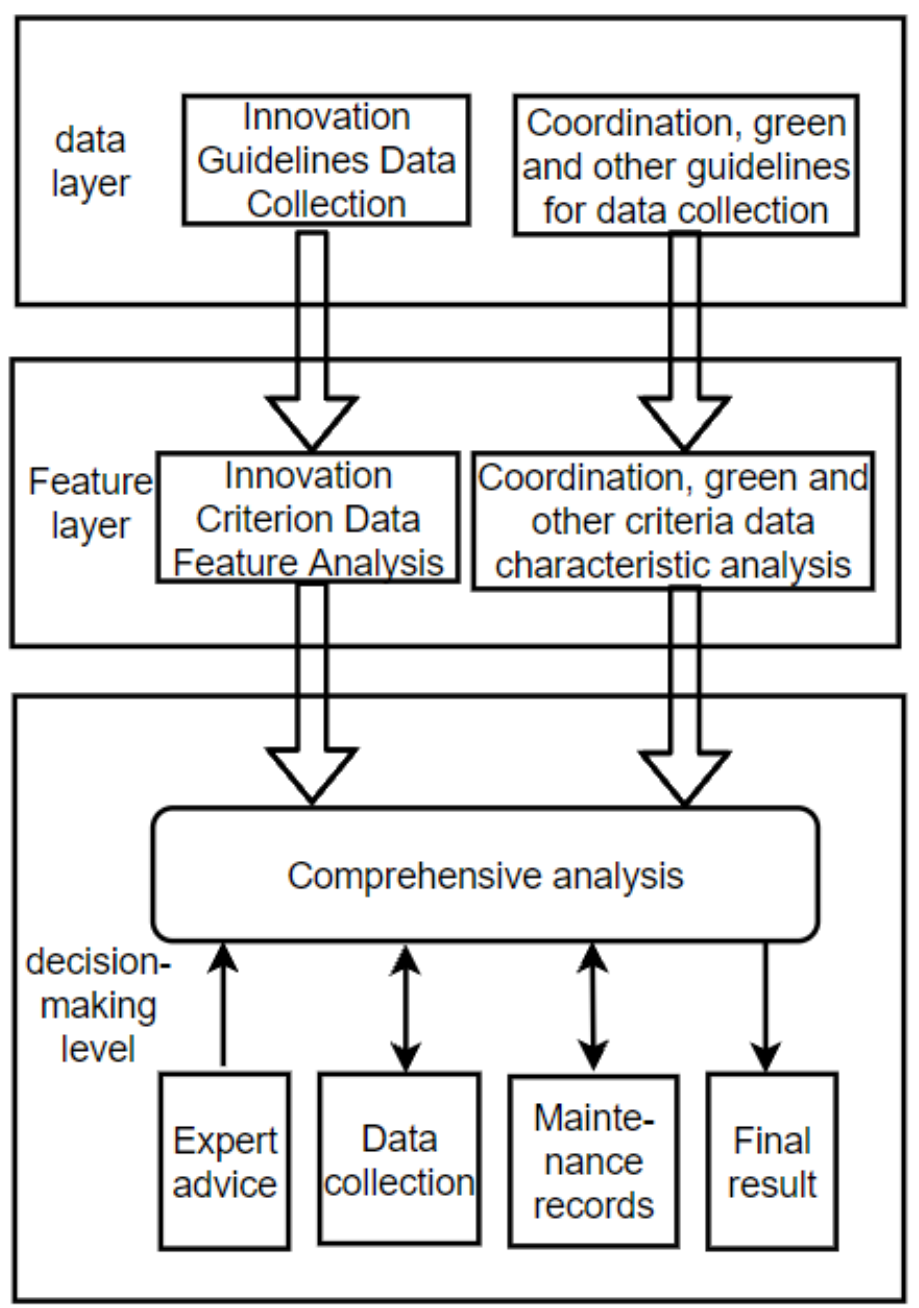

Fig. 2. Information feature extraction system

Statistical data information is entered in the data layer, and the information fusion model is used to fuse the original information from different aspects, so as to maximize the information retention rate, and realize the error correction of the collected data through information fusion.

In the feature layer, based on the fusion results of the data layer, the D-S evidence principle is selected to perform information feature fusion in different aspects. Information is obtained through statistical computing analysis method and neural network analysis method, and feature extraction is carried out after combining the status information obtained by different methods, and information feature fusion is carried out by combining expert knowledge and standard data set in relevant laws and regulations of our country.

According to the information fusion results of the feature layer, the decision-making layer performs further weighted fusion of information features from different aspects in combination with expert advice and collected data, thereby obtaining information features.

\subsection{Model Settings}

In order to test the impact of the development degree of the three types of markets and the development level of digital inclusive finance on the high-quality development of the regional economy, this paper establishes the following benchmark models:

$$
\text { econ }_{i t}=\beta_{0}+\beta_{1} \text { market }_{i t}+\beta_{2} \text { open }_{i t}+\beta_{3} \text { fiscal }_{i t}+\beta_{4} u_{\text {rban }}+\varepsilon_{i}+u_{i t}
$$




$$
\text { econ }_{i t}=\beta_{0}+\beta_{1} \text { finance }_{i t}+\beta_{2} \text { open }_{i t}+\beta_{3} \text { fiscal }_{i t}+\beta_{4} u r b a n_{i t}+\varepsilon_{i}+u_{i t}
$$

In formula (2),econ $i t$ Indicates the high-quality economic development index of the $\mathrm{i}$-th province in the $\mathrm{t}$-th year, market $_{i t}$ represents the marketization index of the ith province in the $t$ year, including the product market development score, the factor market development score and the financial market development score, finance $_{i t}$ , open $_{i t}$, fiscal $_{i t}$ and urban $_{i t}$ respectively represent the inclusive finance development index, trade openness level, fiscal expenditure level and urbanization level of the i-th province in the t-th year. $\varepsilon_{i}$ is fixed effect for region, $\varepsilon_{i t}$ is the random error term vector.

Further, considering the regulatory role of the development level of digital inclusive finance in the impact of marketization development on high-quality economic development, this paper establishes the following model:

$$
\begin{aligned}
& \text { econ }_{i t}=\beta_{0}+\beta_{1} \text { market }_{i t}+\beta_{2} \text { finance }+\beta_{3} \text { market }_{i t} \times \text { finance }_{i t}+\beta_{4} \text { open }_{i t}+\beta_{5} \text { fiscal }_{i t} \\
& +\beta_{6} \text { urban }_{i t}+\varepsilon_{i}+u_{i t}
\end{aligned}
$$

The coefficient of interaction term represents the moderating effect of the development level of digital financial inclusion.

\section{Simulation and Result Analysis}

\subsection{Development Environment}

In the system development process of this paper, Microsoft Visual C++ and SQL Srever2000 database were selected as the system development environment and database. As a visual software development tool, Microsoft Visual $\mathrm{C}++$ is composed of components such as editor and debugger. It has powerful functions and can implement two programming methods, object-oriented and procedural, and can compile different types of Windows programs.

SQL Srever2000 adopts the user/server architecture, which can realize the cooperative operation between different database servers, and realize the creation, configuration and maintenance of the database.

\subsection{Operating Environment}

The $\mathrm{B} / \mathrm{S}$ architecture is selected in the system development process of this paper, which has the characteristics of orderly operation, and the related services of the database server can be used by different terminals.as shown in Fig.3.

Table 2 reports the benchmark empirical test results of the relationship between the development level of financial inclusion, the development degree of the "three markets" and the high-quality economic development. Among them, the Hausman test results rejected the null hypothesis of random effects at the 5\% significance level, so the fixed-effects model was used for analysis. Model (1) is the regression model of financial inclusion on economic growth, models (2)-(4) are the regression models of factor market, product market and financial market respectively on economic growth, and models (5)-(7) are Inclusion of financial inclusion and the three markets into the same framework to consider the impact on economic growth. 


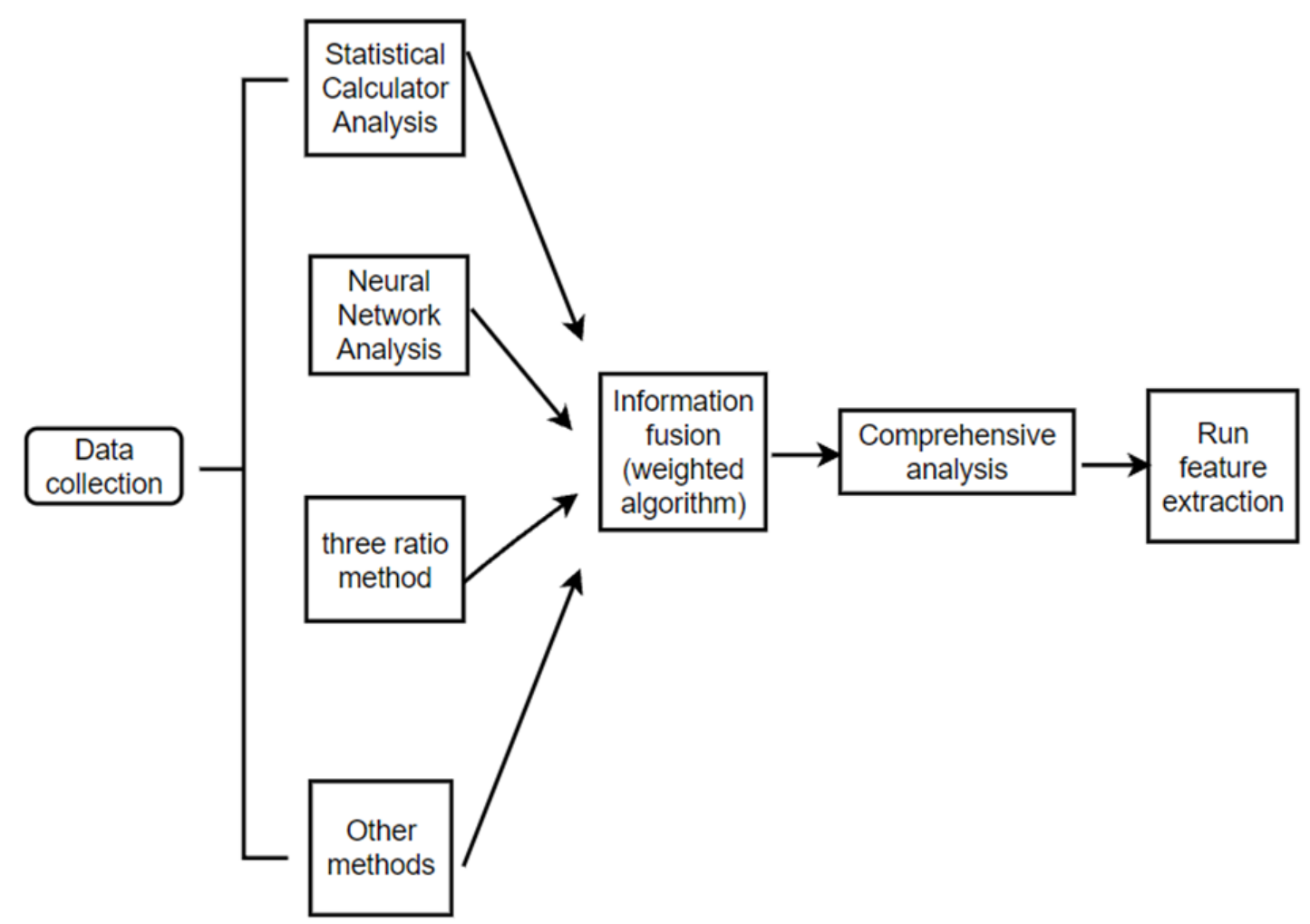

Fig. 3. Analysis process based on information fusion

It can be seen from the estimation results of model (1) that the estimated coefficient of the development level of inclusive finance is significantly positive, indicating that the development of inclusive finance is conducive to promoting high-quality economic development in 31 provinces. From the estimation results of the models (2)(4), it can be seen that the estimated coefficients of the development degree of the factor market, product market and financial market are all significantly positive, indicating that the development degree of the three markets has a significant role in promoting the high-quality development of the regional economy. Hypothesis 2 was confirmed. Comparing and analyzing the regression coefficients of the development level of inclusive finance and the development degree of the three markets, it can be seen that the impact of inclusive finance on the regional economy is less than the impact of the three markets. It can be seen that although inclusive finance has developed, it has not yet reached the original market. influence. Among them, the product market has the largest regression coefficient on the regional economy, indicating that most of the provincial economies in my country are still product-oriented, and factors such as industries, enterprises, and products play a key role in regional economic development. In addition, according to the regression results of models (5)-(7), it can be seen that the inclusion of financial inclusion and the three markets into the unified consideration category still significantly promotes the high-quality development of the provincial economy.

Based on the regression results of the control variables in the benchmark model, it can be seen that trade openness, fiscal expenditure and urbanization level all have a positive role in promoting the high-quality development of the regional economy. Among them, the level of urbanization has the most significant role in promoting it. In addition, when inclusive finance is included in the same model, the regression coefficients of each control variable generally increase, indicating that inclusive finance can promote the development of the region as a whole. 
The System Design and Realization on Inclusive Finance Economic Influence based on the Feature Extraction and Data Fusion

Table 2. Benchmark regression results

\begin{tabular}{|c|c|c|c|c|c|c|c|}
\hline parameter & model (1) & model (2) & model (3) & model (4) & model (5) & model (6) & model (7) \\
\hline Factor & & $\begin{array}{c}0.058^{* *} \\
(2.45)\end{array}$ & & & $\begin{array}{c}0.060 * * * \\
(2.99)\end{array}$ & & \\
\hline Product & & & $\begin{array}{c}0.127 * * \\
(2.34) \\
\end{array}$ & & & $\begin{array}{c}0.135^{* * *} \\
(3.02)\end{array}$ & \\
\hline Finace & & & & $\begin{array}{l}0.082^{*} \\
(1.87)\end{array}$ & & & $\begin{array}{c}0.089 * * * \\
(2.84)\end{array}$ \\
\hline Inclusive & $\begin{array}{c}0.019 * * * \\
(3.36) \\
\end{array}$ & & & & $\begin{array}{c}0.012 * * * \\
(3.81)\end{array}$ & $\begin{array}{c}0.032 * * * \\
(3.78)\end{array}$ & $\begin{array}{c}0.033^{* * *} \\
(4.03)\end{array}$ \\
\hline Open & $\begin{array}{c}0.035^{* *} \\
(2.17)\end{array}$ & $\begin{array}{c}0.038^{* *} \\
(2.35)\end{array}$ & $\begin{array}{c}0.030^{*} \\
(1.85)\end{array}$ & $\begin{array}{c}0.040^{* *} \\
(2.46)\end{array}$ & $\begin{array}{c}0.041 * * * \\
(2.62)\end{array}$ & $\begin{array}{l}0.026 \\
(1.62)\end{array}$ & $\begin{array}{c}0.041 * * * \\
(2.61)\end{array}$ \\
\hline Fiscal & $\begin{array}{c}0.065^{* * *} \\
(6.38)\end{array}$ & $\begin{array}{c}0.042 * * * \\
(4.77)\end{array}$ & $\begin{array}{c}0.049 * * * \\
(5.52)\end{array}$ & $\begin{array}{c}0.044 * * * \\
(4.91)\end{array}$ & $\begin{array}{c}0.063 * * * \\
(6.22)\end{array}$ & $\begin{array}{c}0.071 * * * \\
(7.11)\end{array}$ & $\begin{array}{c}0.067 * * * \\
(6.54)\end{array}$ \\
\hline Urban & $\begin{array}{c}0.438 * * * \\
(7.52)\end{array}$ & $\begin{array}{c}0.381 * * * \\
(6.48)\end{array}$ & $\begin{array}{c}0.387 * * * \\
(6.62)\end{array}$ & $\begin{array}{c}0.395 * * * \\
(6.61)\end{array}$ & $\begin{array}{c}0.429 * * * \\
(7.37)\end{array}$ & $\begin{array}{c}0.442 * * * \\
(7.84)\end{array}$ & $\begin{array}{c}0.455^{* * *} * \\
(7.73)\end{array}$ \\
\hline $\mathrm{C}$ & $\begin{array}{c}-0.468 * * * \\
(-7.52)\end{array}$ & $\begin{array}{c}-0.319 * * * \\
(-6.09)\end{array}$ & $\begin{array}{c}-0.312 * * * \\
(-5.86)\end{array}$ & $\begin{array}{c}-0.303 * * * \\
(-5.55)\end{array}$ & $\begin{array}{c}-0.457 * * * \\
(-7.37)\end{array}$ & $\begin{array}{c}-0.452 * * * \\
(-7.44)\end{array}$ & $\begin{array}{c}-0.447 * * * \\
(-7.14)\end{array}$ \\
\hline $\mathrm{R}^{2}$ & 0.616 & 0.595 & 0.647 & 0.619 & 0.587 & 0.658 & 0.627 \\
\hline
\end{tabular}

\subsection{Extended Sub-sample Empirical Analysis}

In order to further explore the heterogeneity of the adjustment effect of the development level of inclusive finance on the development of the three markets and the high-quality economic development under the differences in the development level of inclusive finance between regions, this paper based on the digital inclusive finance index in each provincial sample period The average value of 31 provinces was divided into three levels of high (High Inc), medium (High Inc), and low (High Inc) inclusive finance development levels for sub-sample regression analysis. The results are shown in Table 3.

From Table 3, it can be seen that the development levels of the three markets and the development level of inclusive finance have a significant positive impact on the high-quality economic development, which is consistent with the regression results of the total sample, indicating that although the development level of inclusive finance in the 31 provinces has However, the development of factors, products and financial markets, and the development of inclusive finance all have a positive effect on economic growth. In contrast, in regions with a high degree of financial inclusion, various markets and financial inclusion have the greatest role in promoting high-quality economic development.

Comparing the coefficients of the interaction terms of high, medium, and low levels of financial inclusion development, we can see that in regions with low levels of financial inclusion, financial inclusion has a significant positive adjustment to the relationship between the three markets and high-quality economic development. and with the increase of the development of inclusive finance, the adjustment effect gradually diminishes. In the regions with the highest degree of financial inclusion, the adjustment effect on the financial market has become insignificant. It can be seen that, as the development of inclusive finance continues to expand its scope and deepen its service system, its coordination effect on the market and economic growth presents an inverted U-shaped nonlinear relationship.

Table 3. Sub-sample regression results based on differences in the degree of development of inclusive finance

\begin{tabular}{|c|c|c|c|c|c|c|c|c|c|}
\hline Parameter & \multicolumn{3}{|c|}{ Hihg Inc } & \multicolumn{3}{|c|}{ Middle Inc } & \multicolumn{3}{|c|}{ Low Inc } \\
\hline Factor & $\begin{array}{c}0.217 * * * \\
(3.88)\end{array}$ & & & $\begin{array}{c}0.086^{* *} \\
(2.07)\end{array}$ & & & $\begin{array}{c}0.124 * * * \\
(5.09)\end{array}$ & & \\
\hline Product & & $\begin{array}{c}0.162 * * \\
(2.46) \\
\end{array}$ & & & $\begin{array}{c}0.136^{* *} \\
(2.38) \\
\end{array}$ & & & $\begin{array}{c}0.035^{* * *} \\
(3.58)\end{array}$ & \\
\hline Finance & & & $\begin{array}{c}0.079 * * \\
(2.35)\end{array}$ & & & $\begin{array}{c}0.031^{* *} \\
(2.06)\end{array}$ & & & $\begin{array}{c}0.072 * * * \\
(5.52)\end{array}$ \\
\hline Inclusive & $\begin{array}{c}0.050 * * * \\
(2.65) \\
\end{array}$ & $\begin{array}{c}0.115^{* *} \\
(1.96) \\
\end{array}$ & $\begin{array}{c}0.010^{* *} \\
(2.28)\end{array}$ & $\begin{array}{l}0.007 \\
(0.68) \\
\end{array}$ & $\begin{array}{c}0.019^{* *} \\
(2.20) \\
\end{array}$ & $\begin{array}{c}0.006^{* *} \\
(2.49)\end{array}$ & $\begin{array}{c}0.044 * * * \\
(5.00) \\
\end{array}$ & $\begin{array}{c}0.017 * * * \\
(4.71) \\
\end{array}$ & $\begin{array}{c}0.022^{* * *} \\
(4.49) \\
\end{array}$ \\
\hline
\end{tabular}




\begin{tabular}{|c|c|c|c|c|c|c|c|c|c|}
\hline Open & $\begin{array}{l}0.039 \\
(1.56)\end{array}$ & $\begin{array}{l}0.034 \\
(1.35)\end{array}$ & $\begin{array}{c}0.068^{* * *} \\
(2.66)\end{array}$ & $\begin{array}{c}0.116^{* * *} \\
(4.07)\end{array}$ & $\begin{array}{c}0.095 * * * \\
(3.08)\end{array}$ & $\begin{array}{c}0.096^{* * *} \\
(2.84)\end{array}$ & $\begin{array}{l}0.016 \\
(0.61)\end{array}$ & $\begin{array}{l}0.015 \\
(0.46)\end{array}$ & $\begin{array}{c}0.073 * * \\
(2.43)\end{array}$ \\
\hline Fiscal & $\begin{array}{c}0.081 * * * \\
(4.30)\end{array}$ & $\begin{array}{c}0.115^{* * * *} \\
(7.24)\end{array}$ & $\begin{array}{c}0.081 * * * \\
(4.02)\end{array}$ & $\begin{array}{c}0.047 * * * \\
(3.03)\end{array}$ & $\begin{array}{c}0.053 * * * \\
(3.97)\end{array}$ & $\begin{array}{c}0.040 * * * \\
(2.59)\end{array}$ & $\begin{array}{c}0.016^{* * *} * \\
(3.52)\end{array}$ & $\begin{array}{c}0.083^{* * *} \\
(3.74)\end{array}$ & $\begin{array}{c}0.022 * * * \\
(5.68)\end{array}$ \\
\hline Urban & $\begin{array}{c}0.533 * * * \\
(3.81)\end{array}$ & $\begin{array}{l}0.178 \\
(1.46)\end{array}$ & $\begin{array}{c}0.387 * * * \\
(2.61)\end{array}$ & $\begin{array}{c}0.406^{* * *} \\
(4.97)\end{array}$ & $\begin{array}{c}0.286^{* * * *} \\
(3.43)\end{array}$ & $\begin{array}{c}0.392 * * * \\
(4.27)\end{array}$ & $\begin{array}{c}0.236^{* * * *} \\
(8.34)\end{array}$ & $\begin{array}{l}0.139 \\
(0.34)\end{array}$ & $\begin{array}{c}0.263^{* * *} \\
(9.29)\end{array}$ \\
\hline $\begin{array}{l}\text { Factor } \times \\
\text { Inclusive }\end{array}$ & $\begin{array}{c}0.034^{* * * *} \\
(3.26)\end{array}$ & & & $\begin{array}{c}0.121^{* * * *} \\
(2.78)\end{array}$ & & & $\begin{array}{c}0.125 * * * \\
(5.46)\end{array}$ & & \\
\hline $\begin{array}{l}\text { Product } X \\
\text { Inclusive }\end{array}$ & & $\begin{array}{c}0.053^{*} \\
(1.89)\end{array}$ & & & $\begin{array}{c}0.055 * * \\
(2.20)\end{array}$ & & & $\begin{array}{c}0.058 * * * \\
(4.37)\end{array}$ & \\
\hline $\begin{array}{l}\text { Finance } X \\
\text { Inclusive }\end{array}$ & & & $\begin{array}{l}0.062 \\
(0.72)\end{array}$ & & & $\begin{array}{c}0.005 * * \\
(2.62)\end{array}$ & & & $\begin{array}{c}0.012 * * * \\
(4.55)\end{array}$ \\
\hline $\mathrm{C}$ & $\begin{array}{c}-0.347 * * \\
(-2.17)\end{array}$ & $\begin{array}{c}-0.922 * * * \\
(-2.64)\end{array}$ & $\begin{array}{c}-0.385 * * * \\
(-2.78)\end{array}$ & $\begin{array}{c}-0.282 * * * \\
(-3.38)\end{array}$ & $\begin{array}{c}-0.326^{* * * *} \\
(-3.06)\end{array}$ & $\begin{array}{c}-0.033^{* *} \\
(-2.06)\end{array}$ & $\begin{array}{c}0.159 * * * \\
(3.10)\end{array}$ & $\begin{array}{c}-0.420 * * * \\
(-3.46)\end{array}$ & $\begin{array}{l}0.015 \\
(0.43)\end{array}$ \\
\hline $\mathrm{R}^{2}$ & 0.583 & 0.793 & 0.447 & 0.563 & 0.690 & 0.531 & 0.805 & 0.329 & 0.807 \\
\hline
\end{tabular}

\subsection{Robustness Check}

In order to further verify the robustness of the results, this paper conducts the following robustness tests: using the six sub-dimensions of the digital financial inclusion index, namely coverage breadth, depth of use, payment, insurance, credit, and digitalization, as alternatives to the financial inclusion development index variables are reestimated. It can be seen from Table 4 that the model estimation results are basically consistent with the previous ones, which further proves that the model established in this paper is robust and the parameter estimation results are highly credible. Due to space limitations, Table 4 only lists the estimated results with coverage as a substitution variable.

Table 4. Robustness test results

\begin{tabular}{|c|c|c|c|}
\hline parameter & model (11) & model (12) & model (13) \\
\hline Factor & $\begin{array}{c}0.071 * * * \\
(2.66)\end{array}$ & & \\
\hline Product & & $\begin{array}{c}0.129 * * * \\
(2.95)\end{array}$ & \\
\hline Finance & & & $\begin{array}{c}0.085^{* * *} \\
(3.49)\end{array}$ \\
\hline Coverage & $\begin{array}{c}0.027 * * \\
(1.75)\end{array}$ & $\begin{array}{c}0.048 * * \\
(2.45)\end{array}$ & $\begin{array}{c}0.038 * * \\
(2.41)\end{array}$ \\
\hline Open & $\begin{array}{c}0.043 * * * \\
(2.67)\end{array}$ & $\begin{array}{c}0.029 * * \\
(1.79)\end{array}$ & $\begin{array}{c}0.042 * * * \\
(2.60)\end{array}$ \\
\hline Fiscal & $\begin{array}{c}0.054 * * * \\
(5.28)\end{array}$ & $\begin{array}{c}0.063^{* * *} \\
(6.15)\end{array}$ & $\begin{array}{c}0.058 * * * \\
(5.74)\end{array}$ \\
\hline Urban & $\begin{array}{c}0.400 * * * \\
(6.59)\end{array}$ & $\begin{array}{c}0.422^{* * *} \\
(7.25)\end{array}$ & $\begin{array}{c}0.410 * * * \\
(6.69)\end{array}$ \\
\hline Factor $\times$ Coverage & $\begin{array}{c}0.015^{* * *} * \\
(4.18)\end{array}$ & & \\
\hline Product $\times$ Coverage & & $\begin{array}{c}0.013 * * * \\
(4.10)\end{array}$ & \\
\hline Finance $\times$ Coverage & & & $\begin{array}{c}0.021 * * \\
(2.47)\end{array}$ \\
\hline $\mathrm{C}$ & $\begin{array}{c}-0.390 * * * \\
(-6.43)\end{array}$ & $\begin{array}{c}-0.389 * * * \\
(-6.42)\end{array}$ & $\begin{array}{c}-0.361 * * * \\
(-5.86)\end{array}$ \\
\hline $\mathrm{R}^{2}$ & 0.574 & 0.649 & 0.619 \\
\hline
\end{tabular}

\section{Summary and Outlook}

Based on the perspective of factor market, product market and financial market, this paper uses my country to establish a panel regression model to explore the impact of the development levels of three markets and the 
development level of inclusive finance on the high-quality development of the regional economy, and the impact of inclusive finance in the three markets respectively. Moderating role in regional economic relations. Further, the samples are divided according to the high-quality economic development level and the development level of inclusive finance, and the heterogeneity of the impact mechanism under different development levels is explored. The results show that the development level of inclusive finance and the development degree of the three markets have a significant positive effect on the high-quality development of the regional economy, and inclusive finance can promote the high-quality development of the regional economy by optimizing the development of the "three markets".

The huge amount of financial data is diverse, random and uncertain. This paper designs an inclusive financial economic impact system based on feature extraction and data fusion. For 31 provincial data, etc., different analysis methods are used to obtain information features, and the features are fused. On the basis of effectively extracting the operational information features of the experimental objects, the system in this paper improves the accuracy of judging the operational status of the experimental objects, which has high application value.

In addition, from the sub-sample regression results, it can be seen that inclusive finance has the most significant adjustment effect on the three markets and high-quality economic development in the high-level economic development level area, followed by the adjustment effect on the middle-level area, and the low-level area. The moderating effect is the smallest; in regions with a low degree of development of inclusive finance, inclusive finance has a significant positive moderating effect on the relationship between the three markets and the level of high-quality economic development, and with the increase in the degree of inclusive finance development, the regulatory effect is gradually weakened.

\section{Acknowledgements}

Funding number: 18YJC029; Beijing Social Science Foundation: Path Analysis and scale measurement of coordinated development of inclusive Finance in Beijing, Tianjin and Hebei to reduce the reverse transfer of wealth.

\section{References}

[1] X. Cheng, X. Yang, F. Zhang, Research on the coordination degree between high-quality development of regional economy and science and technology financial policies, China Soft Science (S1)(2020) 115-124.

[2] J. Du, X.K. Chen, Research on the Income Threshold Effect of Financial Development and Regional Economic Growth, Journal of Beijing Technology and Business University (Social Science Edition) 36(3)(2021) 12-126.

[3] D. Fang, W.B. Ma, The measurement and spatiotemporal characteristics of China's inter-provincial high-quality devel-opment, Regional Economic Review (2)(2019) 61-70.

[4] N. Gu, Y. Liu, Micro-feature analysis of the development of rural inclusive finance in my country, Agricultural Technology and Economics (1)(2018) 48-59.

[5] G.W. He, J. He, Reconsideration of farmers' credit demand and credit availability, Agricultural Economic Issues (2)(2018) $38-49$.

[6] B. Jin, Promoting high-quality development of regional economy with innovative thinking, Regional Economic Review (4)(2018) 39-42.

[7] D.M. Cappelli, A.P. Moore, R.F. Trzeciak, The CERT guide to insider threats: how to prevent, detect, and respond to information technology crimes (Theft, Sabotage, Fraud), City: Addison-Wesley, 2012.

[8] R. Cull, A. Demirgc-Kunt, Financial performance and outreach: A global analysis of leading microbanks, Economic Journal 17(2)(2007) 107-133.

[9] C. Ha, J.C. Yang, S.C. Park, Text categorization algorithms using semantic approaches, corpus—based thesanms and WordNet, Expert Systems with Applications 39(1)(2012) 765-772.

[10]J.F. Liu, L.F. Li, C.Y. Ren, et al., Research on Information Extraction of Coastal Wetland in the Yellow River Estuary Based on Random Forest Model of Feature Optimization, Wetland Science 16(2)(2018) 97-105.

[11]Y.J. Li, J.X. Sun, Fault Diagnosis of Automobile Motor Bearing Based on Two Stages of Feature Extraction and Recognition, Journal of Electronic Measurement and Instrumentation 33(2)(2019) 56-63.

[12]R.H. Schmidt, H.D. Seibel, P. Thomes, From microfinance to inclusive finance: Why local banking works, Weinheim, Germany: Wiley-VCH Verlag, 2016.

[13]Yufang, B.H. Wan, Z.Y. Xiong, Research on feature dimension reduction method in text classification, Computer Application Research 29(7)(2012) 2541-2543.

[14]M. Brunnermeier, D. Palia, K.A. Sastry, Sims C A. Feedbacks: Financial Markets and Economic Activity, American Economic Review 111(6)(2021) 1845-1879. 